\title{
A Peer Survey on Load Frequency Contol in Isolated Power System with Novel Topologies
}

\author{
Namburi Nireekshana, R. Ramachandran, G. V. Narayana
}

\begin{abstract}
Electrical Power systems are paramount intricate system which built by human beings, therefore this type of systems should maintain stable and to get upgrading for upcoming days need multiple control techniques. In these convoluted power systems voltage frequency plays a major role .Hence frequency has to control proper. To control frequency of voltage has three control techniques are primary, secondary and also tertiary frequency control techniques. Thereby second technique also known as Load Frequency Control[1], It is to maintain the desirable frequency even after occurrence of disturbance. Several techniques have been used (like classical, adaptive) to mitigate the power flow disturbances, but drawbacks (parameters tuning, cyber-attacks) are having in these methods. This paper proposes soft computing techniques to build up the operation, control and then stability of the electrical power system.
\end{abstract}

Keywords: load frequency controlling, power system structure, control methods

\section{INTRODUCTION}

The novel power systems status is growing inch by inch because of emergence of low cost, profuse wind, solar and fossil cell energy sources in distributed energy systems[2] as renewable energy sources are giving boosting and digitalization grow thing. These factors may lead to growing of structural power systems[3].

Primary frequency helps out in sustaining the frequency stability of frequency, balancing of the power generation and load consumption pertaining to the grid[3] [4]. When the lack of balance occurs in between load and generation, the frequency of power systems will get change, at that time primary frequency control responds in fastest way. It is automatic control and the purpose is to clear unbalance conditions between source and load, in order to take the system in stable mode[1]. This control is compulsory for all generators in power systems areas . Once primary frequency control finished its work, if the frequency value different from nominal value and power exchange between interconnected systems different from predefined value, therefore it is necessary to restore the nominal frequency[5]. In this situation secondary control comes into picture.

Manuscript received on September 02, 2021.

Revised Manuscript received on September 20, 2021.

Manuscript published on October 30, 2021.

Correspondence Author

Namnuri Nireekshana*, Department of Electrical Engineering, Annamalai University, Annamalai Nagar (Tamil Nadu), India. Email: nireekshan222@gmail.com

R.Ramachandran, Department of Electrical Engineering, Annamala University, Annamalai Nagar (Tamil Nadu), India. Email: ramachandran.auee@gmail.com

G.V.Narayana, Department of Electrical Engineering, JNTU Kakinada, Guntur (A.P), India. Email: gv1.venkata@gmail.com

(C) The Authors. Published by Blue Eyes Intelligence Engineering and Sciences Publication (BEIESP). This is an open access article under the CC BY-NC-ND license (http://creativecommons.org/licenses/by-nc-nd/4.0/)
The secondary frequency control is plays lead role in controlling the frequency in power systems structures like 1,2 , 34 and multi area electrical power systems[6]. Every single area will be allotted with set of generators coupled with each other, which helps in forming an organised group[7]. So that all machines will react simultaneously to changes in load. Firstly, any changes in load are governed by speed governing system[3].

Tertiary frequency control is supreme to restore the session in transmission system operator (TSO).The tertiary control is not automatic but it needs when grid operator's request, its importance follows the same rules of rest of the frequency control techniques_[1]_[8]_In power systems Automatic generated control is a system for adjusting the power flow deviations and frequency of different generators at multiple power plants. Load Frequency Control helps to maintain stable frequency[9] [8]. Therefore Automatic Generated Control is called as Load Frequency Control[10].

\section{A. Objective of Load Frequency Control}

Govern the nominal frequency variations and power flow deviations then outcomes give improvement of the power system stability, operation and control.

\section{REVIEW METHODOLOGY}

Multiple papers reviewed to learn about the importance of load frequency control and knowledge has gained. As a part of extensive review, a reputable and honoured database such as IEEE, Scopus, SCI, Energies, Elsevier. This database has been very helpful to write the article on load frequency control strategies. These are tabulated in table 1 .

Table.1 illustration of review methodology adopted

\begin{tabular}{|c|c|c|}
\hline ID & Number & Usage \\
\hline IEEE & 12 & $60 \%$ \\
\hline Elsevier & 8 & $60 \%$ \\
\hline Energies & 8 & $50 \%$ \\
\hline Books & 5 & $50 \%$ \\
\hline Articles & 7 & $70 \%$ \\
\hline
\end{tabular}

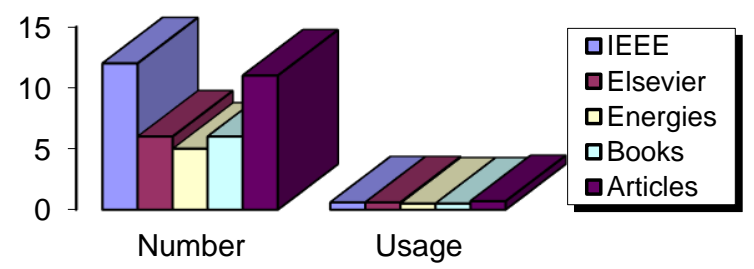

Figure 1.Chart for review methodology adopted 
1. Necessity of frequency as constant value

Few reasons are examined for control the frequency variations.

- The speed of synchronous and asynchronous motors depends on the frequency of supply. Here speed should maintain consistency with follows constant frequency [10].

- If the turbine blades are damaged the generator will stop because of nominal frequency $50 \mathrm{~Hz}$ falls down to $47 \mathrm{~Hz}$ or goes up to 52hz. Therefore should maintain frequency in stable mode.

- In case of power transformer frequency operation conditions, if frequency gets below nominal value, the power transformer winding is over heated and will give low efficiency. Hence frequency values should maintain desired level to get the constant flux for constant voltage [11] [12]

- Most of the AC machines runs by particular speeds which are straight correlated to frequency. Their speed and developed EMF may vary with respect to change in the nominal frequency [13] [14].

- Many devices connected to the grid will only work properly when the input frequency is within certain range[15].

- For parallel power stations running, it is mandatory that frequency of the generators must remain constant for synchronization [16].

- Frequency effects the transmission of interconnected lines[17] [18].

- Household appliances are most sensitive to frequency variations and also gets damaged with changes in frequency.

\section{LITERATURE REVIEW}

\subsection{Control Area Concept Isolated Power System}

Most of the machinery (Generators) in any area incorporate a well-organized family so, that their speed can be controlled with respect to power angle [19] in the sense all the generators are unison with their speed changer setting, load variations, maintaining constant frequency under steady state and dynamic responses .Control area has speed governing , turbine and load models. As shown figure 3.1

Consider

$\mathrm{K}_{\mathrm{p}}=$ gain of the system

$\mathrm{Tp}=$ Power system time constant

$\mathrm{Kg}=$ Generator gain

$\mathrm{Kt}=$ Turbine gain

$\mathrm{Tg}=$ Generator time constant

$\mathrm{Tt}=$ Turbine time constant

$\Delta \mathrm{Pd}=$ Power change in load

$\Delta \mathrm{Pg}=$ Power change in generation

$\Delta \mathrm{F}(\mathrm{s})=$ Change in frequency

$\Delta \mathrm{Xt}(\mathrm{s})=$ Change in steam valve opening

$\mathrm{R}=$ speed regulation of the governor

\subsubsection{Steady state analysis [20]}

Three possible steps are there to get steady state response

1. Constant speed changer setting \& variable load (uncontrollable) [20]

2. Constant load (controllable) \& variable speed changer setting [20]

3. Constant speed changer setting \& constant load[20]

\subsubsection{Dynamic state analysis}

Dynamic response gives the relation between variations in frequency with respect to time for a small change in load for a particular load frequency system[20].

3.2 Speed governing system[21] mainly controls real power flow, which consists of (shown in figure 3.2)

- $\quad$ First stage of Speed governing system

- $\quad$ Second stage of Linkage tool system

- Third stage of Hydraulic elaboration system

- Final stage of acceleration of speed system

\subsubsection{First stage of Speed governing system}

The heart of this system is a fly ball type governing system, which senses the speed or else frequency [20] [21].

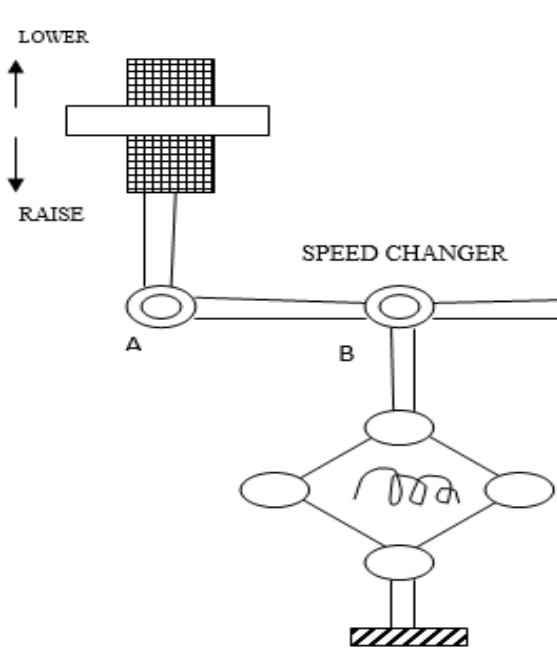

SPEED GOVERNER

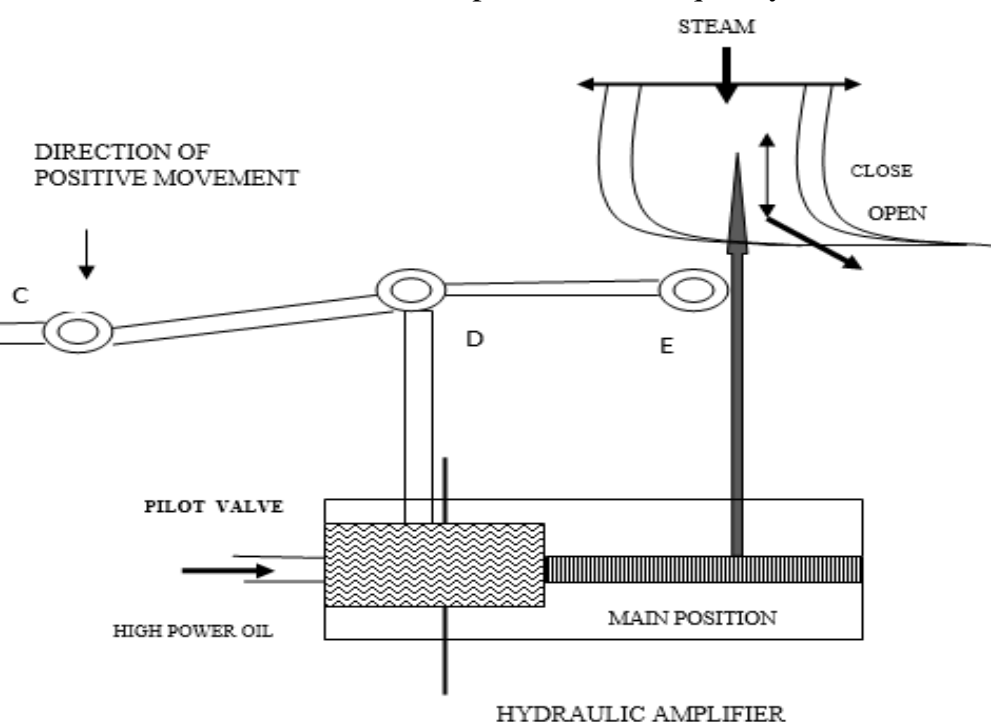

HYDRAULIC AMPLIFIER

Figure 3.2 Speed governing system

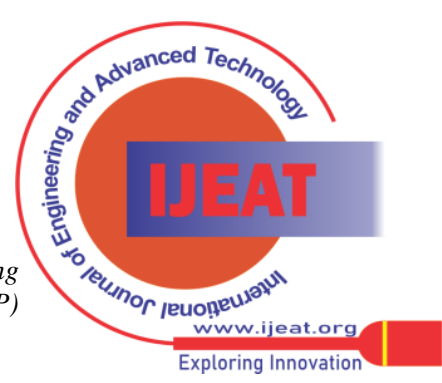




\subsubsection{Second stage of Linkage tool system}

This system yields a moment to control valve position in corresponding to changes in the speed [20] [21].

3.2.3 Third stage of Hydraulic elaboration system

Which consists of main piston and pilot valve[20] [21].

3.2.4. Final stage of acceleration of speed system

An acceleration of speed system produces the steady state power output[20] [21].

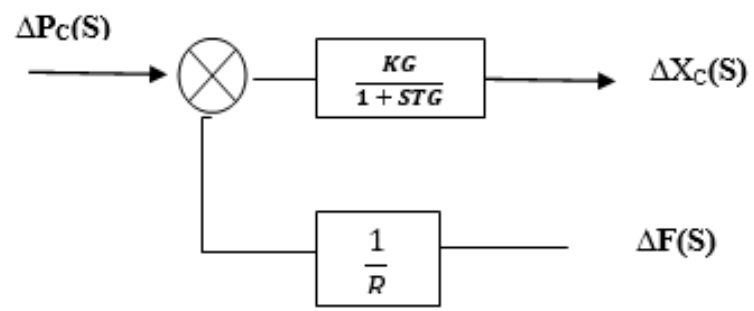

Figure3.2.1. Block diagram of speed governing system

\subsection{Turbine Model}

This model gives the relation between varieties in steam turbine power output and change in steam valve position $\Delta \mathrm{Xt}[20]$.

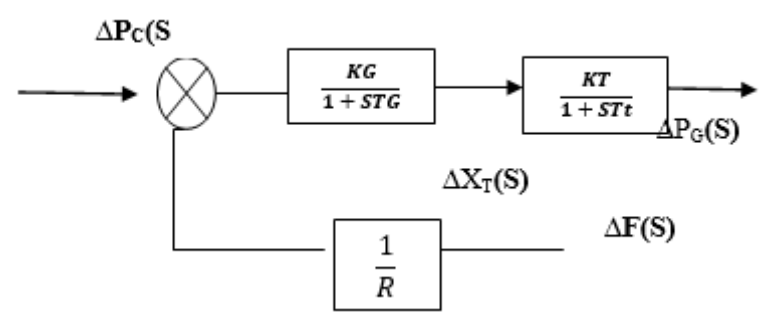

Figure. 3.3. block diagram of turbine model

\subsection{Load Model}

This model offers the relation between time and change in the nominal frequency results in change in generation[21] [20].

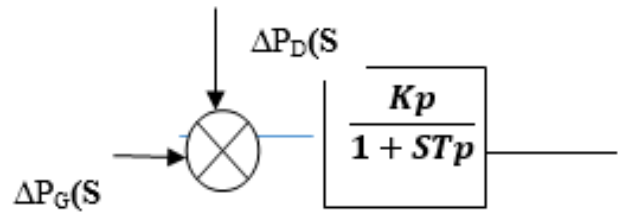

Figure .3.4.Block diagram of load model

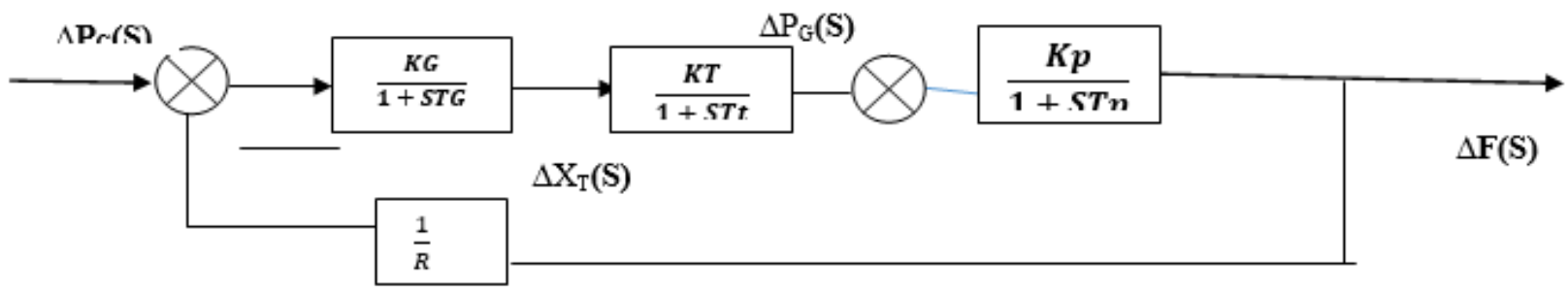

Figure 3.1.Complete diagram of isolated power system

\section{ADOPTED PROPOSAL}

\subsection{Mathematical model of LFC}

Basically, an optimization problem, which of these can be written like F1(t),F2(t)...,Fm(t)[22]

$\mathrm{t}=(\mathrm{t} 1, \mathrm{t} 2 \ldots \mathrm{tm})$

Generally

$\mathrm{Hn}(\mathrm{t})$ equal to $0,(\mathrm{n}=1,2 \ldots)$

$\mathrm{Kn}(\mathrm{t})$ less than or equal to 0 , $(\mathrm{n}=1,2 \ldots)$

And, where F1, F2...Fm are the objectives, and Hn, Kn are the equality and inequality constraints, respectively [22].

If $\mathrm{m}=1 \ldots$ single-objective

$\mathrm{m}=2$, it becomes a multi objective problem and solution scheme is different from single objective [22].

Load frequency control mechanism is basic and simple used in power system operation and control when load varies where an unbalance between active and reactive powers occur. Which control the active power through interconnecting line by sensing the changing power flow[23] [24]. In Interconnected power systems, all areas are interconnected through tie line systems, here any area controlled by control area and tie lines allows power flow among the interconnected systems [25]. If get any small variations in load in any interconnected areas so that the tie line power flow will be disturbed, thereby all areas of output frequencies will be affected. In such type situations must gathered all information about all areas transient state to restore the nominal tie line powers and area frequency in interconnected systems [26]. In interconnected power systems are tied with all other neighbouring systems shown in figure 4.1.

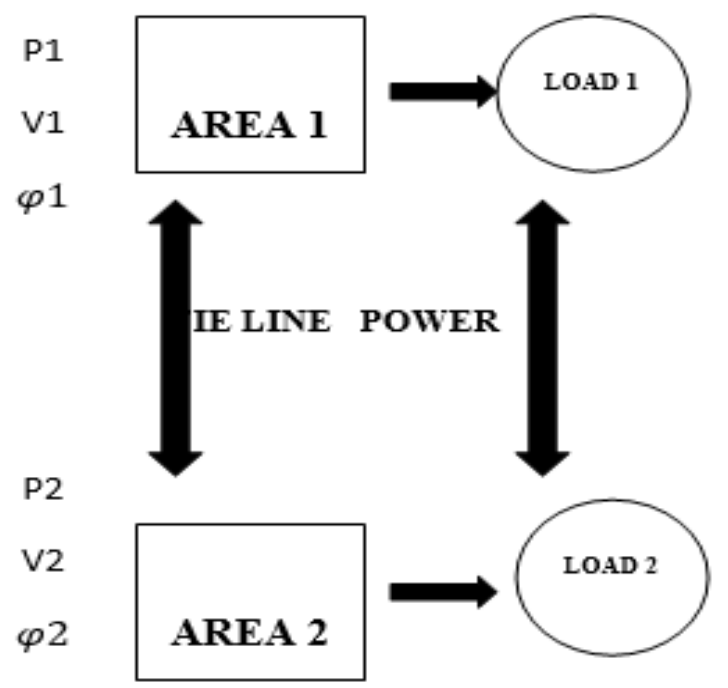

Figure4.1. Two area structured power system

Published By:

Blue Eyes Intelligence Engineering and Sciences Publication (BEIESP)

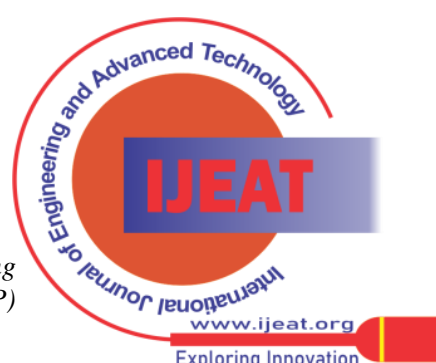




\section{A Peer Survey on Load Frequency Contol in Isolated Power System with Novel Topologies}

Consider two generators are running parallel, in which load changes occures.to get balancing of generators production have various frequency control methods as follows

1. If the P1 generator alone is regulated to have constant frequency, this type of regulation is called flat frequency regulation [21] [27].

2. If both generators $\mathrm{P} 1, \mathrm{P} 2$ are regulate to maintain constant frequency, it is called parallel frequency regulation [21] [27].

3. the generator takes care of the variations in a particular area, there by maintaining the tie line load constant, here to maintain constant frequency is known as flat tie line loading control[21] [27].

Consider

$\varphi 1 \& \varphi 2$

$=$ power angles of equavalent machines of two areas

Pr1= rated capacity of area1

Pr2= rated capacity of area 2

Ptie1=power transmitted from area 1

Ptie2= power transmitted from area 2

T12 \& T21 are the synchronous co efficient

Power transmitted from the area1 is given as

$\mathrm{P}_{\text {tie } 1=} \frac{\mathrm{V} 1 \mathrm{~V} 2}{\mathrm{X} 12} \operatorname{Sin}(\varphi 1-\varphi 2)$

Power transmitted from the area2 is given as
$\mathrm{P}_{\mathrm{tie} 2}=\frac{\mathrm{V} 2 \mathrm{~V} 1}{\mathrm{X} 21} \operatorname{Sin}(\varphi 2-\varphi 1)$

For the incremental changes in power angles the incremental line power can be represented as [27]

$\Delta \mathrm{P}_{\text {tie } 1}=\mathrm{T}_{12}\left(\Delta \varphi_{1}-\Delta \varphi 2\right)$

Where $\mathrm{T}_{12}=\frac{\mathrm{V} 1 \mathrm{~V} 2}{\operatorname{Pr} 1 \mathrm{X} 12} \cos (\varphi 1-\varphi 2)$

For the incremental changes in power angles the incremental line power of area 2 can be represented as

$\Delta \mathrm{P}_{\text {tie } 2}=\mathrm{T}_{21}(\Delta \varphi 2-\Delta \varphi 1)$

Where $\mathrm{T}_{21}=\frac{\mathrm{V} 2 \mathrm{~V} 1}{\operatorname{Pr} 2 \mathrm{X} 21} \operatorname{CoS}(\varphi 2-\varphi 1)$

\subsection{Classification of LFC adoptive techniques}

To bring the frequency under one palm in all areas of this interconnected system, LFC will be adopted few control strategies[10] [28]. These techniques will be helpful in maintaining constant tie line frequency and control the power flow disturbances. These control techniques are beneficial for the normal and abnormal conditions of loads to get the real frequency and power of pre specified value[29] [30]. Control techniques are classical, adaptive, intelligent and soft computing types[31]. Based on application of control will be picked from them. The total classifications shown in figure.4.2

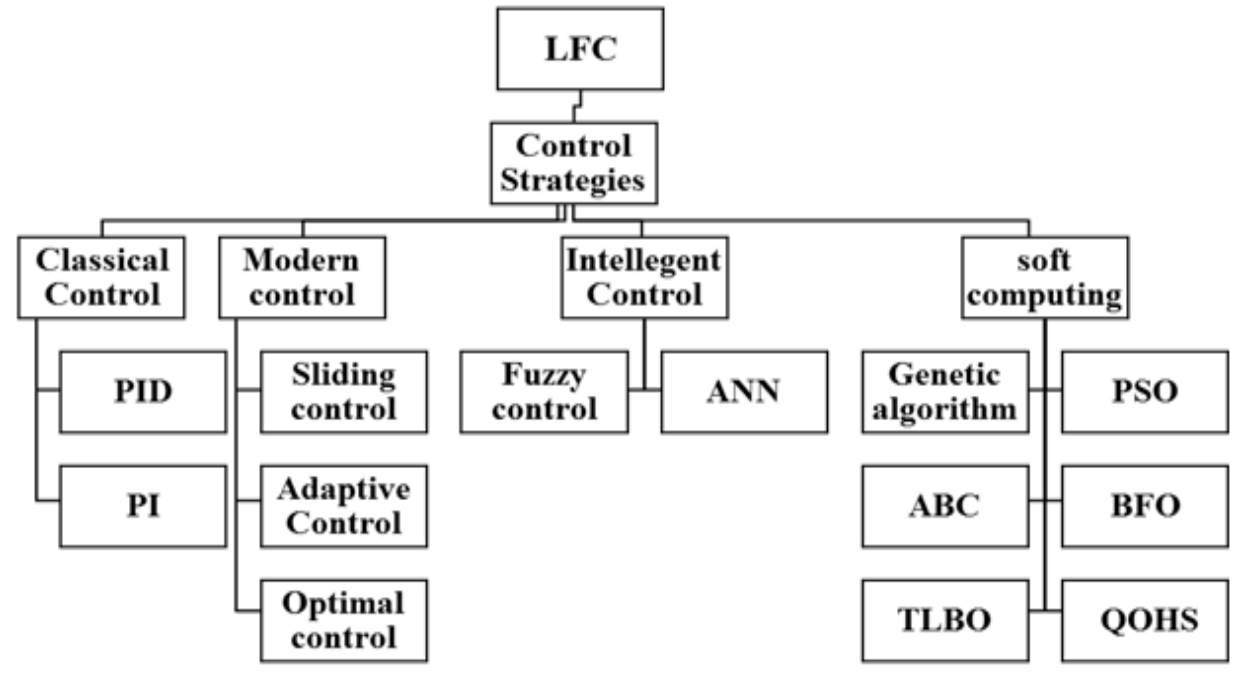

Figure 4.2. Classifications of LFC control techniques

In classical control strategies mostly used techniques are PID and PI .These techniques help to set the actual frequency and power from a process predefined value or set point as possible. And also help to analyze the phase margin and gain margin using nyquist and bode pot methods. But these classical techniques are poor in optimally tuning the parameters of load frequency, robustness and cyber-attack issues[32].

In modern control or optimal control strategies commonly involved methods are sliding control, adaptive control and optimal control[33]. These methods are developed to provide the solution, system has state variable models such as system state vector, therefore this type of control techniques are given accurate solutions, if all the state variable are consider to design closed loop control systems. But these strategies are lag performance in large scale power system applications[9].

In intelligent control strategies fuzzy and ANN are strongly involed. This type of techniques help to govern the frequency and power issues[9]. In order to mitigate the load

frequency and power of tie line of interconnected systems in power system structure, have to be analysed the peak over shoot, peak undershoot and setting time [34].

Therefore intelligent control strategies can easily analyse the above responses and establish the solution. But these techniques are lag in explicit parameters identification. Sometimes controller is complicated and unrealistic[35].

Finally soft computing methods are frequently used and get benefited in inter connected systems for load frequency control[31]. In which mostly used control schemes are G.A, PSO.ABC, BFO, TLBO and QOHS.These techniques are made to solve nonlinear problems and introduced the human intelligence such as cognition, recognition, understanding, and learning by means of these control schemes involve to reach tractability and robustness on simulating the human decision-making behavior with $\operatorname{cost}[36]$. desirable

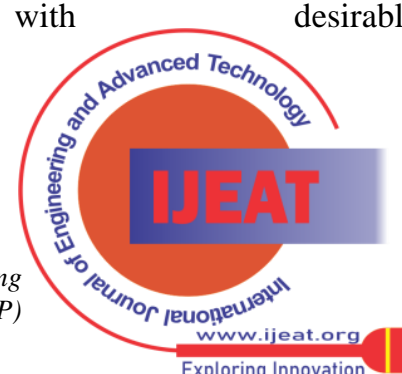


Genetic algorithm provides consistency of tuning of parameters, the load parameters changes accordingly load. Conventional control schemes cannot maintain consistency of tuning of parameters[37], but GA can do.GA provides desirable dynamic response for the control system.

PSO stands particle Swarm Optimization is one of the finest method in soft computing control scheme family to supervise the frequency and power. It is helps to find approximate solution to difficult maximization or minimization problems. It is easy and simple algorithm to implement. Which scheme is used to solve the frequency regulation problems in inter connected systems[38].

ABC stands Artificial Bee Colony have investigated from the intelligent scavenge honey bees behaviour. This ABC algorithm is specifically based on model of scavenge behaviour of honey bee colonies [39]. The model contains three parts such as employee and unemployed foraging bees, and food sources. The first two components, employed, unemployed foraging bees search for third component i.e. rich food sources. Therefore in this method, a colony of artificial forager bees like agents search for wealthy artificial food sources. In order to analyze the system nominal frequency and tie-line power flow with respect load changes, ABC scheme have been used[40].
BFO stands Bacterial Foraging Optimization was developed based on nature-inspired optimization method, this one is taken based on the bacteria's foraging behavior. In LFC this scheme provides clampdown of oscillations in power system. And also helps to analyze for optimal controller parameters by keep down the time domain analysis.

TLBO stands Teaching Learning Based Optimization is a teaching-learning process developed algorithm and it is made on the impact of a teacher on the outcomes of students in a the lecture hall. TLBO involve to solve continuous as well as disjoined optimization problems in single or multiple objectives. This scheme consists of two modes of operations such as teacher and learner point of views. This mechanism is used to brush up the transient response of the structure of the power systems [41].

Generally Fertilizers are used to kill insects on the cotton field and many methods have been adopted to market the cotton for good profit using natural fertilizers and farming methods as well as There are several methods used to obtain quality power by controlling the frequency based on various load applications in the power system areas[42]. Some of them are listed in the table2

Table 2 Load Frequency Analysis

\begin{tabular}{|c|c|c|}
\hline Structural Power Systems & Control techniques & Novel Applications \\
\hline $\begin{array}{l}\text { multi area power systems } \\
\text { - Single } \\
\text { - Two } \\
\text { - Three }\end{array}$ & $\begin{array}{ll}\text { - } & \text { PID } \\
\text { - } & \text { Centralized \& } \\
& \text { decentralized } \\
\text { - } & \text { GA } \\
\text { - } & \text { PSO } \\
\text { - } & \text { FUZZY } \\
\text { - } & \text { ANN } \\
\text { - } & \text { Variable structure } \\
& \text { control }\end{array}$ & $\begin{array}{ll}\cdot & \text { HVDC } \\
\text { - } & \text { Deregulation } \\
\text { - } & \text { Distributed energy } \\
& \text { generation } \\
\text { - } & \text { Smart grid } \\
\text { - } & \text { Micro grid }\end{array}$ \\
\hline
\end{tabular}

\section{CONCLUSION}

Soft computing methods are increasingly playing a major role in controlling the frequency of the load in the electrical structured power system area to suit the present days conditions. Therefore better results can be obtained by using soft computing techniques for govern the nominal frequency and power flow disparities and also mitigate these problems.

\section{REFERENCES}

1. H. H. Alhelou, M.-E. Hamedani-Golshan, R. Zamani, E. Heydarian-Forushani, and P. Siano, "Challenges and opportunities of load frequency control in conventional, modern and future smart power systems: a comprehensive review," Energies, vol. 11, no. 10, p. 2497, 2018.

2. B. K. Bose, "Power electronics in renewable energy systems and smart grid: Technology and applications," 2019.

3. R. M. Elavarasan, "Comprehensive review on India's growth in renewable energy technologies in comparison with other prominent renewable energy based countries," J. Sol. Energy Eng., vol. 142, no. 3, p. 030801, 2020. Á. Molina-García, "Power systems with high renewable energy sources: A review of inertia and frequency control strategies over time," Renew. Sustain. Energy Rev., vol. 115, p. 109369, 2019.

5. H. R. Chamorro, F. R. S. Sevilla, F. Gonzalez-Longatt, K. Rouzbehi, H. Chavez, and V. K. Sood, "Innovative primary frequency control in low-inertia power systems based on wide-area RoCoF sharing," IET Energy Syst. Integr., vol. 2, no. 2, pp. 151-160, 2020.

6. N. Jaleeli, L. S. VanSlyck, D. N. Ewart, L. H. Fink, and A. G. Hoffmann, "Understanding automatic generation control," IEEE Trans. Power Syst., vol. 7, no. 3, pp. 1106-1122, 1992.

7. S. K. Pandey, S. R. Mohanty, and N. Kishor, "A literature survey on load-frequency control for conventional and distribution generation power systems," Renew. Sustain. Energy Rev., vol. 25, pp. 318-334, 2013.

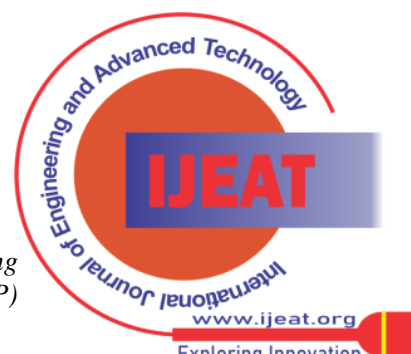


8. A. Aziz, A. T. Oo, and A. Stojcevski, "Analysis of frequency sensitive wind plant penetration effect on load frequency control of hybrid power system," Int. J. Electr. Power Energy Syst., vol. 99, pp. 603-617, 2018.

9. H. Shayeghi, H. A. Shayanfar, and A. Jalili, "Load frequency control strategies: A state-of-the-art survey for the researcher," Energy Convers. Manag., vol. 50, no. 2, pp. 344-353, 2009.

10. H. H. Alhelou, M.-E. Hamedani-Golshan, R. Zamani, E. Heydarian-Forushani, and P. Siano, "Challenges and opportunities of load frequency control in conventional, modern and future smart power systems: a comprehensive review," Energies, vol. 11, no. 10, p. 2497, 2018.

11. D. J. Perreault et al., "Opportunities and challenges in very high frequency power conversion," in 2009 Twenty-Fourth Annual IEEE Applied Power Electronics Conference and Exposition, 2009, pp. 1-14.

12. D. Cochrane, D. Y. Chen, and D. Boroyevic, "Passive cancellation of common-mode noise in power electronic circuits," IEEE Trans. Power Electron., vol. 18, no. 3, pp. 756-763, 2003.

13. M. Comanescu and L. Xu, "An improved flux observer based on PLL frequency estimator for sensorless vector control of induction motors," IEEE Trans. Ind. Electron., vol. 53, no. 1, pp. 50-56, 2006.

14. D. G. Holmes and A. Kotsopoulos, "Variable speed control of single and two phase induction motors using a three phase voltage source inverter," in Conference Record of the 1993 IEEE Industry Applications Conference Twenty-Eighth IAS

15. R. Teodorescu, M. Liserre, and P. Rodriguez, Grid converters for photovoltaic and wind power systems, vol. 29. John Wiley \& Sons, 2011.

16. S. Barsali, M. Ceraolo, P. Pelacchi, and D. Poli, "Control techniques of dispersed generators to improve the continuity of electricity supply," in 2002 IEEE Power Engineering Society Winter Meeting. Conference Proceedings (Cat. No. 02CH37309), 2002, vol. 2, pp. 789-794.

17. M. Kheradmandi and M. Ehsan, "Dynamic analysis of transmission line connection in restoration of interconnected power systems," in Canadian Conference on Electrical and Computer Engineering 2004 (IEEE Cat. No. 04CH37513), 2004, vol. 3, pp. 1621-1624.

18. P. Alitalo, O. Luukkonen, L. Jylha, J. Venermo, and S. A. Tretyakov, "Transmission-line networks cloaking objects from electromagnetic fields," IEEE Trans. Antennas Propag., vol. 56, no. 2, pp. 416-424, 2008.

19. A. Dhamanda and A. K. Bhardwaj, "Automatic generation control of thermal generating unit by using conventional and intelligent controller," Int. J. Electr. Eng. Technol., vol. 5, no. 10, pp. 56-64, 2014.

20. A. Chakrabarti and S. Halder, Power System Analysis: Operation And Control 3Rd Ed. PHI Learning Pvt. Ltd., 2010.

21. A. J. Wood, B. F. Wollenberg, and G. B. Sheblé, Power generation, operation, and control. John Wiley \& Sons, 2013.

22. J. Chen, J.-H. Yin, and C. F. Lee, "The use of an SQP algorithm in slope stability analysis," Commun. Numer. Methods Eng., vol. 21, no. 1, pp. 23-37, 2005.

23. M. R. Tur and R. Bayindir, "A Review of Active Power and Frequency Control in Smart Grid," in 2019 1st Global Power, Energy and Communication Conference (GPECOM), 2019, pp. 483-488.

24. Y. G. Rebours, D. S. Kirschen, M. Trotignon, and S. Rossignol, "A survey of frequency and voltage control ancillary services-Part I: Technical features," IEEE Trans. Power Syst., vol. 22, no. 1, pp. 350-357, 2007.

25. A. N. Venkat, I. A. Hiskens, J. B. Rawlings, and S. J. Wright, "Distributed MPC strategies with application to power system automatic generation control," IEEE Trans. Control Syst. Technol., vol. 16, no. 6, pp. 1192-1206, 2008. Annual Meeting, 1993, pp. 613-620.

26. R. D. Christie and A. Bose, "Load frequency control issues in power system operations after deregulation," IEEE Trans. Power Syst., vol. 11, no. 3, pp. 1191-1200, 1996.

27. G. Kusic, Computer-aided power systems analysis. CRC Press, 2018.

28. M. S. Estrice, "Design of control strategies for frequency stability of PV-thermal interconnected power system," PhD Thesis, 2021.

29. C. K. Shiva and V. Mukherjee, "Automatic generation control of interconnected power system for robust decentralized random load disturbances using a novel quasioppositional harmony search algorithm," Int. J. Electr. Power Energy Syst., vol. 73, pp. 991-1001, 2015.

30. H. Haes Alhelou, M. E. Hamedani-Golshan, T. C. Njenda, and P. Siano, "A survey on power system blackout and cascading events: Research motivations and challenges," Energies, vol. 12, no. 4, p. 682, 2019.

31. R. Malhotra, N. Singh, and Y. Singh, "Soft computing techniques for process control applications," Int. J. Soft Comput. IJSC, vol. 2, no. 3, pp. 32-44, 2011.

32. K. S. Rajesh and S. S. Dash, "Load frequency control of autonomous power system using adaptive fuzzy based PID controller optimized on improved sine cosine algorithm," J. Ambient Intell. Humaniz. Comput., vol. 10, no. 6, pp. 23612373, 2019

33. D. Wang, H. He, and D. Liu, "Intelligent optimal control with critic learning for a nonlinear overhead crane system," IEEE Trans. Ind. Inform., vol. 14, no. 7, pp. 2932-2940, 2017.

34. A. Pappachen and A. P. Fathima, "Load frequency control in deregulated power system integrated with SMES-TCPS combination using ANFIS controller," Int. J. Electr. Power Energy Syst., vol. 82, pp. 519-534, 2016.

35. A. Rodríguez-Molina, E. Mezura-Montes, M. G. VillarrealCervantes, and M. Aldape-Pérez, "Multi-objective metaheuristic optimization in intelligent control: A survey on the controller tuning problem," Appl. Soft Comput., vol. 93, p. 106342, 2020.

36. K. Kumar and G. S. M. Thakur, "Advanced applications of neural networks and artificial intelligence: A review," Int. J. Inf. Technol. Comput. Sci., vol. 4, no. 6, p. 57, 2012.

37. F. Daneshfar and H. Bevrani, "Load-frequency control: a GA-based multi-agent reinforcement learning," IET Gener. Transm. Distrib., vol. 4, no. 1, pp. 13-26, 2010.

38. Y. Del Valle, G. K. Venayagamoorthy, S. Mohagheghi, J.-C. Hernandez, and R. G. Harley, "Particle swarm optimization: basic concepts, variants and applications in power systems," IEEE Trans. Evol. Comput., vol. 12, no. 2, pp. 171-195, 2008.

39. P.-W. TSai, J.-S. Pan, B.-Y. Liao, and S.-C. Chu, "Enhanced artificial bee colony optimization," Int. J. Innov. Comput. Inf. Control, vol. 5, no. 12, pp. 5081-5092, 2009.

40. D. Karaboga and B. Basturk, "On the performance of artificial bee colony (ABC) algorithm," Appl. Soft Comput., vol. 8, no. 1, pp. 687-697, 2008.

41. R. V. Rao, V. J. Savsani, and D. P. Vakharia, "Teachinglearning-based optimization: a novel method for constrained mechanical design optimization problems," Comput.-Aided Des., vol. 43, no. 3, pp. 303-315, 2011.

42. R. Shankar, S. R. Pradhan, K. Chatterjee, and R. Mandal, "A comprehensive state of the art literature survey on LFC mechanism for power system," Renew. Sustain. Energy Rev., vol. 76, pp. 1185-1207, 2017.

Published By:

Blue Eyes Intelligence Engineering

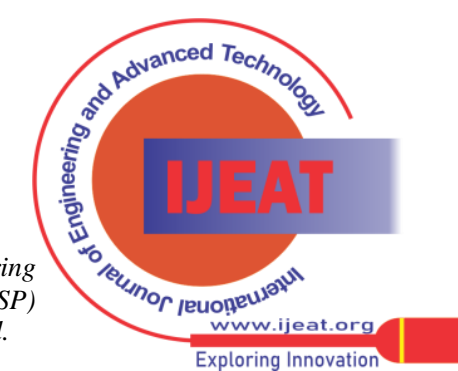




\section{AUTHOR'S PROFILE}

Namburi Nireekshana, graduated from JNTU Hyderabad with $75 \%$ aggregate and received Master of Technology from JNTU Hyderabad with $76 \%$, research scholar in Annamalai University under the esteemed guidance of Dr.

M. Ramachandran and Dr. GV. Narayana. He is working on load frequency control area.

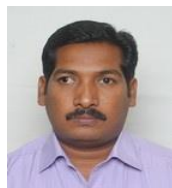

Ramachandran.R, working as Assistant Professor in Annamalai University in Electrical Engineering Department. He awarded PhD degree on deregulated power system, power system analysis, transmission system. He has 19 years of teaching experience.

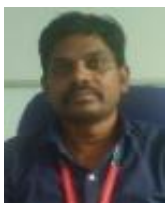

G.V. Narayana, is working as Professor and HOD, in Guntur Engineering College in Electrical and Electronics Engineering Department. He received $\mathrm{PhD}$ on advances in min-max fair power flow tracing for loss allocation.

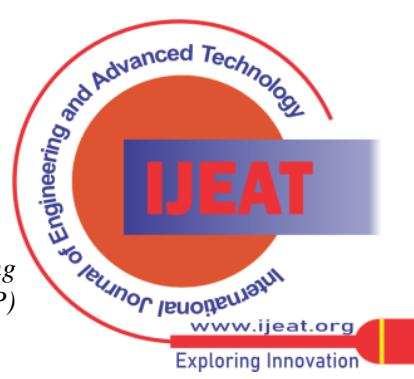

